\title{
BACTERICIDAL ACTION OF SODIUM SULFAPYRIDINE AND OF A GLUCOSE-SULFAPYRIDINE SOLUTION IN HUMAN BLOOD
}

\author{
By FRANCIS C. LOWELL, WILLIAM C. SPRING, JR., AND MAXWELL FINLAND \\ (From the Thorndike Memorial Laboratory, Second and Fourth Medical Services (Harvard), \\ Boston City Hospital and the Department of Medicine, Harvard Medical School, Boston)
}

(Received for publication September 5, 1939)

The importance of careful biological control of new chemotherapeutic agents is generally conceded. It is not always fully appreciated, however, that similar control may be equally essential when a chemical of known activity and of proven efficacy is used in some new manner. In this paper we wish to present evidence that treatment of a chemical with proven antipneumococcic activity in a simple manner, such as might be used to facilitate its administration, may alter its antibacterial properties materially.

In a previous paper (1) we presented data which indicated that sulfapyridine in concentrations usually attainable in therapy has marked bacteriostatic and considerable bactericidal effects on pneumococci grown in favorable artificial media. The same properties were also demonstrated when this drug was added to human blood in vitro or when it occurred in the blood of patients under treatment (2). The low solubility of this compound and the desirability of having greater concentrations in solution for parenteral administration led to the use of glucose as a medium to effect such solubility. With 50 per cent glucose in water, it was found possible to obtain the complete solution of 25 per cent or more of sulfapyridine, but boiling was necessary to bring this about. Clinical tests indicated that such a solution containing 10 per cent sulfapyridine could be given intravenously and subcutaneously without ill effects, provided only that it was diluted to isotonicity with respect to the glucose when given by the latter route (3).

This glucose-sulfapyridine solution was used for detailed studies of the blood concentrations and urinary excretions after administration by various routes and also for comparisons, in these respects, to sulfapyridine, sodium sulfapyridine and sulfanilamide. These studies, which are reported separately (4), gave indirect evidence that a new compound was formed which had proper- ties different from sulfapyridine with respect to absorption, excretion, distribution in the body and renal clearance. A limited clinical trial indicated that, while mild cases apparently responded favorably, those with typical pneumonia did not seem to show a response consistent with the full activity of the original drug (3).

The present paper deals with studies of the pneumococcidal properties of human blood to which this glucose-sulfapyridine solution was added in vitro and similar studies with blood of patients following the administration of this solution by various routes. Comparable studies with sodium sulfapyridine are also presented.

\section{MATERIALS AND METHODS}

The pneumococcidal tests were carried out as in the other studies mentioned $(1,2)$. The stock Type III pneumococcus was used. Preliminary tests with this organism in the blood of each of the subjects used in these studies showed either no pneumococcidal action, or only 10 diplococci were killed in $0.5 \mathrm{cc}$. of blood. Control tests with these bloods repeated at the time of the in vitro experiments and also just prior to the administration of the drugs gave the same results. The glucose-sulfapyridine solution was prepared by the Research Division of the Lederle Laboratories and was furnished in sealed ampules each containing $50 \mathrm{cc}$. of the sterile solution equivalent to 25 grams of glucose and approximately 5 grams of sulfapyridine. Only freshly opened vials were used in order to minimize the possibility of hydrolysis. The concentrations of sulfapyridine in the blood were determined by the method of Marshall and Litchfield (5). Presumably any sulfapyridine present in chemical combination with glucose is hydrolyzed during the determination of "free" sulfapyridine by this method. This must be borne in mind whenever values for "free" sulfapyridine are given, since the amounts present in combination with glucose were not determined separately. There was no significant change in the $\mathrm{pH}$ of the broth media when sodium sulfapyridine was added in the concentrations used in these tests. In all in vitro tests, the drugs were added to $0.5 \mathrm{cc}$. of blood in a volume of $0.1 \mathrm{cc}$. of saline containing sufficient amounts to bring the final concentration of sulfapyridine in the blood to $10 \mathrm{mgm}$. per $100 \mathrm{cc}$. $(1: 10,000)$. 


\section{RESULTS}

Effect of glucose-sulfapyridine and sodium sulfapyridine when added to defibrinated blood in vitro

The results of pneumococcidal tests with the blood of 2 subjects are given in Table I. The blood of subject $\mathrm{S}$ was used on two occasions, 1 week apart. On both occasions the addition of glucose-sulfapyridine solution in amounts equivalent to $10 \mathrm{mgm}$. per $100 \mathrm{cc}$. $(1: 10,000)$ did not

TABLE I

Pneumococcidal action of sodium sulfapyridine and of glucose-sulfapyridine when added to defibrinated human blood in vitro

\begin{tabular}{|c|c|c|c|c|c|c|}
\hline \multirow{2}{*}{$\underset{\text { ject }}{\text { Sub- }}$} & \multirow{2}{*}{$\begin{array}{c}\text { Material } \\
\text { added }\end{array}$} & \multirow{2}{*}{$\begin{array}{c}\text { Concentra- } \\
\text { tion }\end{array}$} & \multicolumn{2}{|c|}{$\begin{array}{l}\text { Growth } \\
\text { inhibition }\end{array}$} & \multicolumn{2}{|c|}{$\begin{array}{l}\text { Pneumococcidal } \\
\text { action at } 48 \text { hours }\end{array}$} \\
\hline & & & $\underset{\text { hours }}{24}$ & $\begin{array}{c}48 \\
\text { hours }\end{array}$ & $\begin{array}{l}\text { Inocu- } \\
\text { lum }\end{array}$ & Growth \\
\hline $\mathbf{S}$ & $\begin{array}{c}0 \\
\text { G.SP. }\end{array}$ & $\begin{array}{c}\text { mgm. per } 100 \\
\text { cc. } \\
10\end{array}$ & $\begin{array}{r}0 \\
10\end{array}$ & $\begin{array}{l}0 \\
0\end{array}$ & & \\
\hline $\mathbf{S}^{*}$ & $\begin{array}{c}0 \\
\text { G.SP. } \\
\text { SP. } \\
\text { Glucose }\end{array}$ & $\left.\begin{array}{l}10 \\
10 \\
50\end{array}\right\}$ & $\begin{array}{c}0 \\
0 \\
10^{5}\end{array}$ & $\begin{array}{c}0 \\
0 \\
10^{5}\end{array}$ & $\begin{array}{l}10^{5} \\
10^{4}\end{array}$ & $\begin{array}{r}96 \\
0\end{array}$ \\
\hline $\mathbf{F}$ & $\begin{array}{c}\text { 0 } \\
\text { G.SP. } \\
\text { NaSP. } \\
\text { SP. }\end{array}$ & $\begin{array}{l}10 \\
10 \\
10\end{array}$ & $\begin{array}{c}10 \\
0 \\
10^{4} \\
10^{5}\end{array}$ & $\begin{array}{c}10 \\
0 \\
10^{4} \\
10^{5}\end{array}$ & $\begin{array}{l}10 \\
10^{3} \\
10^{5} \\
10^{4}\end{array}$ & $\begin{array}{r}10 \\
0 \\
1200 \\
0\end{array}$ \\
\hline $\mathrm{Ft}$ & $\begin{array}{c}\mathbf{0} \\
\text { G.SP. } \\
\text { NaSP. }\end{array}$ & $\begin{array}{l}10 \\
10\end{array}$ & $\begin{array}{c}0 \\
10^{2} \\
10^{5}\end{array}$ & $\begin{array}{c}0 \\
0 \\
10^{4}\end{array}$ & $\begin{array}{l}10^{4} \\
10^{3} \\
10^{2}\end{array}$ & $\begin{array}{l}8 \\
8 \\
0\end{array}$ \\
\hline
\end{tabular}

* Blood taken 1 week later.

† Same blood kept at $37^{\circ} \mathrm{C}$. for 30 hours. The drugs were added prior to incubation.

\section{Explanation of Tables $I$ and II}

Amount. In the case of the glucose-sulfapyridine this represents total amounts of sulfapyridine in the solution. Concentration. Given in mgm. per 100 cc. When added in vitro, the final concentration is given, except the glucose, for which the added concentration is given. Growth inhibition. Numbers represent the largest inoculum which showed no color change.

Pneumococci killed. Listed only when inhibition was noted. Growth = number of colonies grown in agar pour plates. Inoculum refers to original number. Larger inocula yielded too many colonies to count, smaller ones yielded no growth.

Abbreviations: SP. = sulfapyridine

G.SP. = glucose-sulfapyridine solution

$\mathrm{NaSP}$. = sodium sulfapyridine

I.V. = intravenous

S.C. = subcutaneous

P.O. = oral. result in any pneumococcidal activity. That this lack of activity was not due to the presence of glucose as such was shown by the fact that, when both glucose and sulfapyridine were added in the same proportions as those originally present in the glucose-sulfapyridine solution, there was marked pneumococcidal action. The extent of this action was the same as when no glucose was added (1).

The blood of subject $F$ killed 10 diplococci when first tested. The same fresh blood showed no pneumococcidal activity when glucose sulfapyridine was added, but considerable numbers were killed and the growth of even larger numbers was inhibited after the addition of sulfapyridine or its sodium salt.

\section{Effect of incubation at $37^{\circ} \mathrm{C}$.}

Duplicate control tests and tests with the addition of glucose sulfapyridine and sodium sulfapyridine were carried out with the blood of subject $F$ after incubation for 30 hours before the organisms were added. There was no bactericidal activity in the blood without the drug. Slight inhibition of growth for 24 hours occurred in the blood containing glucose-sulfapyridine, while inhibition and killing in the blood containing sodium sulfapyridine were essentially the same as in the fresh blood.

The loss of the small amount of pneumococcus killing in the blood of subject $\mathrm{F}$ after incubation is consistent with the destruction of complement which is essential for the activation of natural pneumococcidal action of human serum $(6,7)$.

Tests with blood obtained after administration of glucose sulfapyridine by various routes and of sodium sulfapyridine intravenously

Glucose sulfapyridine was given intravenously, subcutaneously, and orally, and blood samples taken at arbitrary intervals thereafter were tested for their action on Type III pneumococci. In addition, a number of samples of blood obtained from the glucose-sulfapyridine recipients were allowed to stand at $37^{\circ} \mathrm{C}$. for varying lengths of time and the tests repeated. Tests were also made with the blood of 2 subjects after the intravenous injection of sodium sulfapyridine. The results of all these tests are shown in Table II. After parenteral injection of the glucose-sulfa- 
TABLE II

Pneumococcidal tests with defibrinated human blood after administration of glucose-sulfapyridine solution or of sodium sulfapyridine

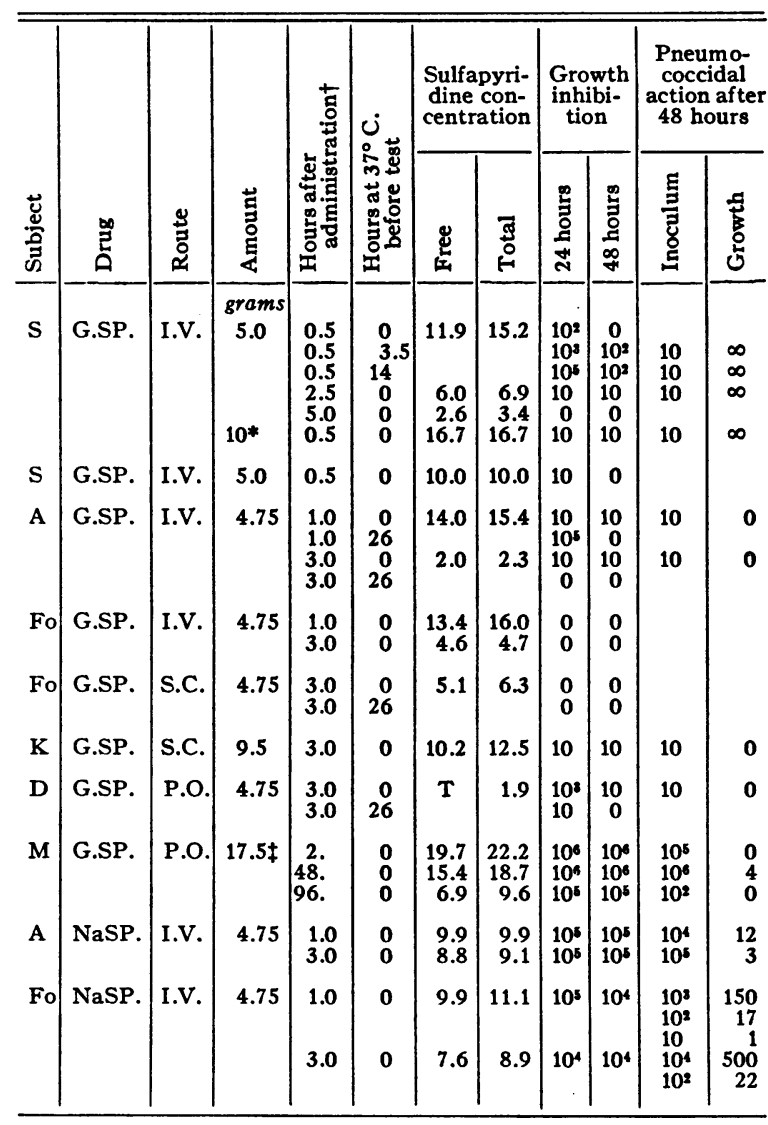

* Second injection of 5 grams 5 hours after the first. $\dagger$ From beginning of administration - each dose given in 1 hour except in Subject $S$ who received it in $1 \frac{1}{2}$ hours. All parenteral injections were given in $500 \mathrm{cc}$. of normal saline.

$\ddagger 5$ grams, then 2.5 grams, 4 hourly for 5 doses. Hours given are after the last dose. Fluids were given liberally during this period.

pyridine solution practically no pneumococcidal action was noted even when high concentrations of drug were present in the blood. After preliminary incubation of these blood samples at $37^{\circ} \mathrm{C}$., varying degrees of growth inhibition occurred, depending on the level of the drug and the length of time allowed for incubation. In subject $A$, the freshly-shed blood on two occasions killed 10 diplococci and no killing occurred following incubation, but the growth of a large number was inhibited. This again suggests that, as with the in vitro experiment, the small amount of killing was due to the immune mechanism rather than to the action of the drug, the activity being abolished by the inactivation of complement and perhaps the death of leukocytes in the process of incubation.

Following the intravenous injection of sodium sulfapyridine, there was marked bacteriostatic and moderate bactericidal action comparable to the effects noted from the addition of this drug in vitro, as noted above. This was also similar to the action of sulfapyridine added to blood in vitro (1) or when present in blood after its oral administration (2).

The results of the tests carried out with the blood taken after the oral administration of the glucose-sulfapyridine solution were in sharp contrast to those already noted with the blood obtained after parenteral administration of the same solution. The pneumococcidal action was the same as after the intravenous injection of the sodium salt or after the oral administration of the unaltered sulfapyridine. The high concentration maintained in the blood of $\mathrm{M}$ for such a long interval is associated with the delayed absorption which was shown to be characteristic of the glucose sulfapyridine when given orally (4).

\section{DISCUSSION}

The results of the bactericidal tests reported here and the studies on absorption and excretion (4) are in essential agreement. They indicate that a new compound is formed by boiling sulfapyridine in 50 per cent glucose. This glucosesulfapyridine solution differs from the original sulfapyridine and also from the sodium sulfapyridine in the rate in which it is cleared by the kidneys after parenteral administration, as well as in its distribution in the body fluids when given by such routes. The bactericidal tests show further that this glucose-sulfapyridine solution is inert when added in vitro or when given parenterally. On standing in blood at $37^{\circ} \mathrm{C}$., some hydrolysis takes place, releasing sufficient sulfapyridine to bring about varying degrees of growth inhibition but not enough to effect any appreciable killing of the Type III pneumococci used. The method used here for determining the concentration of free sulfapyridine also causes hydrolysis of the glucose compound, giving values which include both free sulfapyridine and sulfapyridine combined with glucose. 
When the glucose-sulfapyridine solution is given orally, on the other hand, the material that is absorbed into the blood has the same properties, as regards both its renal clearance and its bactericidal action as free sulfapyridine. Here again, the compound is presumably hydrolyzed after ingestion, freeing sulfapyridine in an active form which then has the same clearance and bactericidal properties as uncombined sulfapyridine or its sodium salt. This hydrolysis after oral ingestion presumably takes place slowly, since absorption of the sulfapyridine into the blood has been shown to be considerably delayed as compared with the absorption of sulfapyridine as such (4).

In this study as in the others $(1,2)$, simultaneous tests for opsonins were carried out and the pneumococcidal action of sulfapyridine was shown to be entirely independent of phagocytosis. The data are omitted since the results were negative throughout.

\section{SUMMARY AND CONCLUSIONS}

The bactericidal action of a 10 per cent solution of sulfapyridine in 50 per cent glucose was tested against a susceptible strain of Type III pneumococcus in human blood in vitro, and after its administration by the intravenous, subcutaneous and oral routes.

When added in vitro and after its parenteral administration this solution was found to be essentially inert. Blood to which similar amounts of sodium sulfapyridine are added in vitro or blood which is obtained after the intravenous administration of this compound has bacteriostatic and pneumococcidal properties similar to those of sulfapyridine.
After oral ingestion of the glucose-sulfapyridine solution the bactericidal power of the blood is the same as that resulting from equivalent concentrations of free sulfapyridine. Absorption, however, is slower than after sulfapyridine taken orally.

These studies were carried out with the technical assistance of Mildred W. Barnes and Claire Wilcox. The chemical determinations were made by Margaret A. Adams and Nancy E. Marean.

\section{BIBLIOGRAPHY}

1. Spring, W. C., Jr., Lowell, F. C., and Finland, M., Studies on the action of sulfapyridine on pneumococci. J. Clin. Invest., 1940, 19, 163.

2. Finland, M., Spring, W. C., Jr., and Lowell, F. C., Immunological studies on patients with pneumococcic pneumonia treated with sulfapyridine. J. Clin. Invest., 1940, 19, 179.

3. Finland, M., Lowell, F. C., Spring, W. C., Jr., and Taylor, F. H. L., Parenteral sulfapyridine. The intravenous use of sodium sulfapyridine and a report of clinical and laboratory observations on the use of glucose-sulfapyridine solution. Ann. Int. Med. (In press).

4. Taylor, F. H. L., Lowell, F. C., Spring, W. C., Jr., and Finland, M., A comparative study of the blood concentrations and urinary excretions after single doses of sulfapyridine and related compounds administered by various routes. J. Clin. Invest., 1940, 19, 201.

5. Marshall, E. K., Jr., and Litchfield, J. T., Jr., Determination of sulfanilamide. Science, 1938, 88, 85.

6. Robertson, O. H., Graeser, J. B., Coggeshall, L. T., and Harrison, M. A., The relation of circulating antipneumococcal immune substances to the course of lobar pneumonia. I. Natural immune substances. J. Clin. Invest., 1934, 13, 621.

7. Ward, H. K., and Enders, J. F., An analysis of the opsonic and tropic action of normal and immune sera based on experiments with the pneumococcus. J. Exper. Med., 1933, 57, 527. 